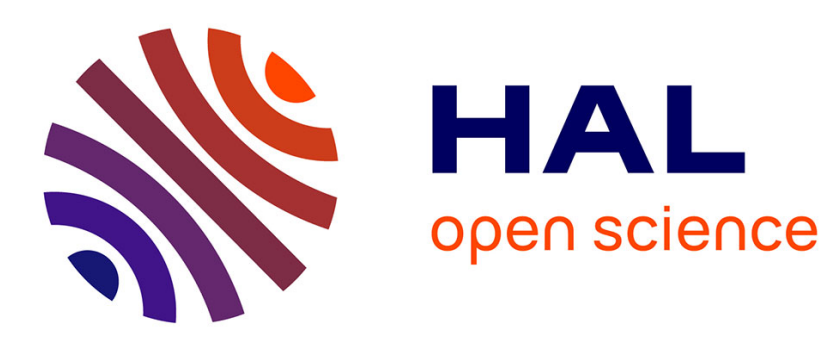

\title{
Using TRIZ in the Healthcare Environment: First Proposition of a New Design Method
}

\author{
Axel Degland, Camille Jean, Claude Gazo
}

\section{To cite this version:}

Axel Degland, Camille Jean, Claude Gazo. Using TRIZ in the Healthcare Environment: First Proposition of a New Design Method. 19th International TRIZ Future Conference (TFC), Oct 2019, Marrakesh, Morocco. pp.429-437, 10.1007/978-3-030-32497-1_34. hal-02905536

\section{HAL Id: hal-02905536 \\ https://inria.hal.science/hal-02905536}

Submitted on 23 Jul 2020

HAL is a multi-disciplinary open access archive for the deposit and dissemination of scientific research documents, whether they are published or not. The documents may come from teaching and research institutions in France or abroad, or from public or private research centers.
L'archive ouverte pluridisciplinaire HAL, est destinée au dépôt et à la diffusion de documents scientifiques de niveau recherche, publiés ou non, émanant des établissements d'enseignement et de recherche français ou étrangers, des laboratoires publics ou privés. 


\title{
Using TRIZ in the healthcare environment: first proposition of a new design method
}

\author{
Axel Degland ${ }^{1}$, Camille Jean ${ }^{1}$ and Claude Gazo $^{1}$ \\ ${ }^{1}$ Arts et Métiers ParisTech - Laboratoire Conception de Produits et Innovation, \\ 151 boulevard de l'Hôpital, 75013 Paris
}

\begin{abstract}
Design in the healthcare environment is challenging. More than in the other activity sectors, it requires to take the users (patients and medical staff) as experts in the loop. This article will describe the bases of a new design method integrating TRIZ concepts for the healthcare environment. A first case study will be presented on the design of an exoskeleton specialized in the assistance of hemiplegic patients during their re-education.
\end{abstract}

Keywords: Design thinking, TRIZ, Biomechanics, Robotic, healthcare.

\section{$1 \quad$ Introduction}

Designing a device that should be used in healthcare is a demanding process due to the standards in terms of quality, security and functionality. This involves that companies often interact lately with patients and doctors, working with them mainly during test phases. But this tendency to rely on the company's vision of the patients and doctors' need for the product can create a gap between the final product and the need. This problem becomes detrimental in public healthcare where funds and human resources are often limited. Those resources, may they be human or financial, end up being drained by products and projects that are not tuned to their need.

This paper will detail the design of an exoskeleton for post stroke hemiplegia rehabilitation. Stroke is sudden shortage of the brain's air supply leading to the death of cerebral cells [1]. Aftermaths of such an event can lead to psychological and neurological deficiencies [2]. One of the most frequent sequels is hemiplegia, the paralysis of one or more limb located on the same part of the body. This means that a hemiplegic patient will not be able to move the limbs on the right or left of his body but not both [3].

The lack of control of the limbs is due to the decay of the motor control centers of the brain which are frequently damaged during strokes. This means that the patients' muscles are healthy and that the problem lies inside the brain [4]. The control is damaged but not the limbs. But the brain can change its disposition, brain activity associated with a certain function can change location. This concept is called neuroplasticity and 
is the pivot around which all the hemiplegia rehabilitation revolves around. The therapy's goal is to stimulate the muscles in order to trigger the brain recovery process and heightened neuroplasticity [5-6].

With the rise of computer sciences, robot assisted reeducation raised from a single paper theme to a full-on discipline and some companies have built themselves around the design of exoskeleton and other robotic devices for rehabilitation [7-8]. Studies in laboratory suggest that robot assisted therapies have a real impact on the recovery of patients, helping them recover quicker than therapies that don't incorporate robotic means of exercise and papers about the design of similar exoskeleton have already emerged [9].

\section{Goals}

This paper investigates a new creativity and user centered design process using TRIZ allowing the integration of patients and medical personnel in the early design phase. Those future users of the device will be treated as experts in phases where technical experts are normally predominant. Concepts for the actuation of limbs will be generated and will be rated in term of creativity, feasibility and pertinence in order to qualify the pertinence of our proposition.

\section{$3 \quad$ Methodology}

\subsection{Global methodology of the project}

As we aim at integrating the patients and doctors in our design process, we chose to start from the basis of design thinking, a method that already integrates the users, and add elements in order to enhance the participation of users. The main addition to the process will be the addition of TRIZ elements, especially the notions of ideality and the contradictions networks. Papers suggest that the combination of the two process can lead to a better problem-solving process. [10]

Design thinking is a method that includes the experience and knowledge of the user in the conception of the product [11-13]. It revolves around the concept of empathy, which is the understanding of what the user knows, want and need. But it also implies that the user should not be used solely for analyzing the problem but also during all the steps toward the final product. The user should be a full member of the team, placing all the steps in perspective. Another specificity of this process is the use of retroaction loops. The idea being that the process isn't linear but that steps should be interconnected, allowing the team to go back to previous parts of the project to quickly adjust what is needed before coming back to the current phase. This allows the team to adapt faster if a dissonance between the device and the expressed need is detected than more classic design method that are often reluctant on going backward. 
Design thinking as defined by Stanford University can be resumed by 5 steps expressed as actions: empathize, define, ideate, prototype [12]. During the Empathize phase the team will discuss with the users in order to understand them, what they want, what they know, what they need. The idea is to create an empathic bond with the users in order to better understand the context. During the Define phase the team will define the problematic and the need. The user is still involved and validate the pertinence of the team's conclusions. It is also the phase where the team redact the specifications. The Ideate step is the problem solving one, the team will use the knowledge gained during the previous phases in order to solve the problems that they identified during the defined phase. The user should be involved in the process. The Prototype phase is used to prototype the solutions the team came up with during the previous step. Finally, the Test step is the one when users will be confronted to the prototypes and establish if the solutions are adequate to their problems. As the users have been heavily involved during all the previous phases, this phase is used in order to establish the ameliorations to the products rather than to test the adequacy to the need [14-15].

TRIZ is a problem solving and analysis tool based on patterns of invention in patents literature. This tool is used to analyze a system in order to identify technical locks, establish contradictions and solve them [16]. Our goal being the integration of TRIZ inside the design thinking process, we changed the steps to integrate more TRIZ elements in the first three steps (empathize, define, ideate) where the impact of the patient experience could be the most significant.

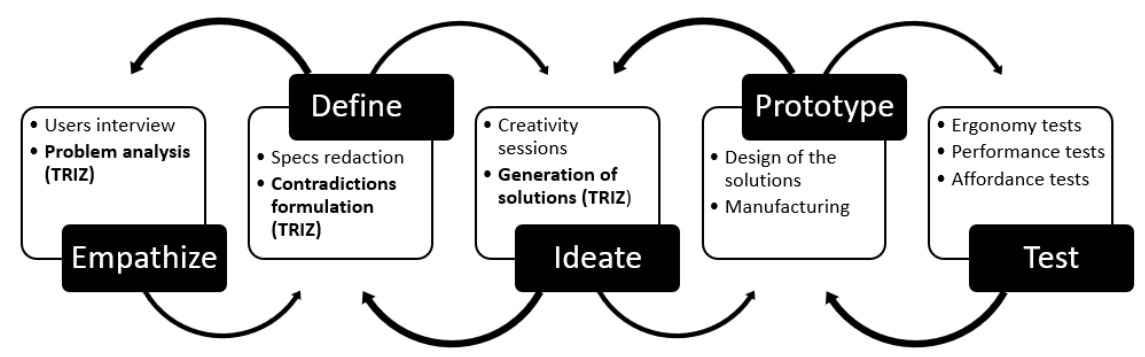

Figure 1 - Schematization of the new method

This new method keeps the basic structure of design thinking but integrate TRIZ elements in the different steps. The notion of feedback loops is still present as each step can impact the previous one. Each step is using different experts in its process: technical experts (engineers), field experts (doctors and patients) and TRIZ experts. Not all the experts are involved in each step. Empathize and define step involve the three types of expert but not the ideate step that only involve the TRIZ and technical experts. 


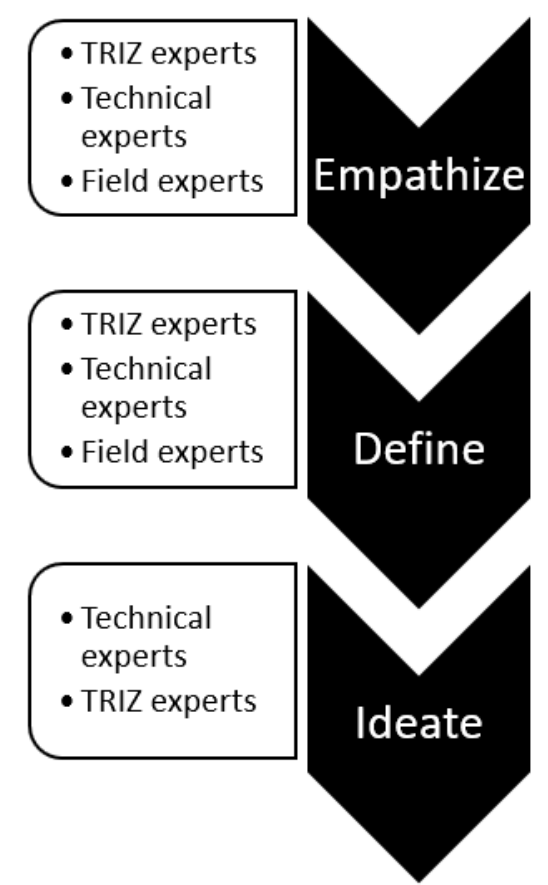

Figure 2 - Illustration of the experts involved in each phase

We will now explain the content of each step and how the TRIZ method is integrated inside each step. As said earlier we will focus on the first three steps (Empathize, Define, Ideate).

\subsection{Empathize phase}

The Empathize step is the core of the Design Thinking method. As the problems that need to be solved are rarely the ones faced by the design team, it is important for them to understand who the users are, what they need and how they feel about it. During this phase, the goal is to link with the users in order to understand and integrate their needs and the problematics they encounter during the use of products similar to the one the team is designing. In medical environment, this is important as recovery processes are difficult and put much stress on both patients and medical personnel, it is difficult for healthy person to grasp naturally the challenges that the users face daily.

The designer is supposed to observe the user in its environment in order to understand their behaviors and the situation. In our case study, during this step a rehabilitation center was visited in order to better understand the rehabilitation process and its challenges. This visit was also prepared extensively by a strong bibliographic study in order to understand the general process first. This allowed us to confront a more scholar approach and the reality of the process. 
Then the designer should engage with the patient. They stop being observers and start involving themselves with their future users (medical personnel and patients). Typically, this is done by interviews that can be either by phone or in person. In our case study, two rehabilitation team managers, a physiotherapist and a patient were contacted for those interviews. Of all the interviewees, we only met one of the team managers in person, all the other were only met by phones due to busy schedules. The interviews were oriented toward the rehabilitation process, the user experience and the use of robotic means of recovery (like the upper limbs Armeo exoskeleton or the lower body Lokomat exoskeleton). The content of each interview wasn't fixed beforehand, and each interlocutor had the freedom to stir the conversation toward points they felt were important.

TRIZ was incorporated during this period by establishing a session of problem modeling soon after the end of the interviews. The idea is to analyze the problem with a user centered approach. 4 persons participated in the session: a TRIZ expert, an engineer that had conducted the interviews, an engineer acting as biomechanical expert and a designer outside of the project. The recovery process and the already existent exoskeleton were analyzed, focusing on the actuation of the limbs. But after discussing about the user experience, the session moved toward problems that were more in touch with the user's problems and we end up focusing on the hip articulation and the patientexoskeleton interfaces. TRIZ allowed us to identify more easily the priorities and moving swiftly toward more primordial problems while keeping in mind the user experience.

\subsection{Define phase}

The Define step is centered around the definition of the problems and the expressions of the goals. In engineering processes, it can be linked to the redaction of the specifications. The idea of this step was for us to use the knowledge and experience gathered during the previous step in order to structure our project and the idea of the product.

We wrote the specification for our product and while doing it we also established contradiction models for future TRIZ sessions. In order to keep the users (patients and doctors) in the loop we shared the specifications and contradiction models with the users that helped us during the Empathize phase. Doing this we established a link between the users and the technical team that allowed us to keep the user feedback and integrate it inside our work.

The idea being that we expressed to them our vision of the exoskeleton and the rehabilitation while translating the specifications in terms that people with no technical background could understand. Our contradiction problems evolved from the feedback as the medical personnel could establish parallels between their knowledge and the technical models. Certain problems that we expressed became irrelevant as the physiotherapists counterbalanced it during sessions while other things that we judged the responsibility of the medical team became specifications for the exoskeleton. 


\subsection{Ideate phase}

The Ideate phase is the time to generate ideas and solutions that respond to the problem defined during the earlier steps. In our case study, the participants consisted of 2 automations specialists, 3 biomechanics specialists, an ergonomist and a product design specialist. The team was gathered for a 3-hour session. During this session, the results of the previous step were used in order to explain the problem to the participants. During the Empathize phase we used TRIZ to analyze the problem, the result of this was used during the Define phase to establish contradictions and problematics models. These models were presented and explained to the participants of the session as well as some notions of TRIZ (ideality, principle of final ideal result and contradiction principle). The participants used this in the ideation part of the session in order to generate concept.

The session consisted of a short recap of the project so far followed by a presentation of the technical contradiction identified during the define phase. After that the team chose on which contradiction to focus. The rest of the session was creativity oriented, consisting of a purge exercise, an inversion exercise and an ideation phase. The purge is a simple exercise, every participant notes key words on sticky notes and show them to the others. After that, the team gather and create poles of information, grouping the notes by categories they chose. The goal is to express everything they know and think about the subject in order to create a common pool of knowledge from where to gather later. The inversion is an exercise in which the team express the worst version of the product they can imagine and then use it to express an ideal version of the product. By doing so they identify functions that the product needs to fulfill and technical lock. Here it helped the team take in account the perception that patients would have of the product. After doing this, the team generated ideas for solutions. They focused on the actuation of the patient limbs. Rather than generating an important number of concepts and ideas, the team focused on generating solutions that were not already used and discuss on the technical locks identified during the inversion and the contradictions identified during the TRIZ session of the Define phase.

Elements that were identified during the previous phase of the project and that were presented to the participants were naturally used by them during the idea generation. They linked those elements with the results of the purge and inversion in order to build solutions based on the problem and their own knowledge.

Comparing this to classic creativity sessions, the integration of TRIZ components (the contradictions, the notion of ideality and sub/super systems) allowed the team to used creativity without losing touch with the technical aspect of the project. Solutions were detailed and the team laid the path for future TRIZ session on each sub systems. This will be detailed later in the results section of this article. 
At the end of the session, it was decided to loop back to the empathize step in order to detail the exercises used during the rehabilitation. Doing so would allow us to start a new TRIZ process, focusing on sub systems rather than the complete exoskeleton.

\section{$4 \quad$ Results}

At the end of the session, we identify, for each solution, if TRIZ was used. The results in term of creativity, feasibility and pertinence of the ideas produced during the creativity session will be examined here.

During the session, the participants generated 14 ideas based on 5 axes of thinking. The axes correspond to principle of solutions from which they worked in order to construct their solutions (example: axis 2 regroup solution based on motors bound to the leg). In each of these axes, a certain number of solutions were generated by using the elements introduced with TRIZ.

\begin{tabular}{|l|c|c|c|c|c|}
\hline Axis $N^{\circ}$ & $\mathbf{1}$ & $\mathbf{2}$ & $\mathbf{3}$ & $\mathbf{4}$ & $\mathbf{5}$ \\
\hline Number of solutions & 6 & 2 & 2 & 2 & 2 \\
\hline Number of solutions integrating TRIZ & 6 & 1 & 0 & 1 & 1 \\
\hline
\end{tabular}

Table 1 - Solutions per axis

When generating the solutions, participants could rely solely on creativity or TRIZ or even combine the two, taking an idea that was based on creativity and integrating TRIZ notions in order to make it evolve. In the figure below, the solutions that used or were based solely on TRIZ are noted in red while ideas that came from creativity are noted in black.

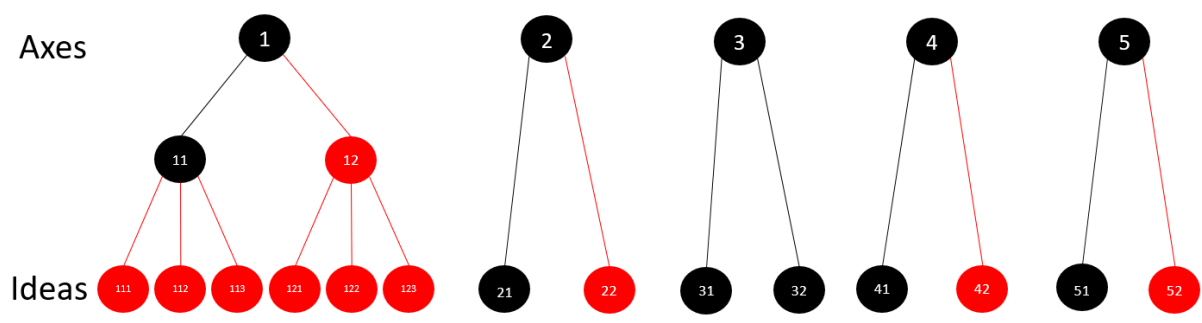

Figure 3-Schematization of the generation of solutions (black: Classic creativity; red: TRIZ creativity)

As seen in the figure, participants used TRIZ in order to improve ideas they came up with during creativity. This is visible in the first axis of solution where they generated ideas based solely on TRIZ but also used it to create new solutions based on one they 
imagined during the creativity. Ideas 111,112 and 113 are based on creativity but integrated solutions that came from the use of TRIZ for the generation of ideas 121, 122 and 123. Without the use of TRIZ, the team would have imagined 1 solution for this axis, but by adding TRIZ notions and applying them to other axes of thinking, they came up with 6 solutions only for the axis 1 . It can be suggested that the use of TRIZ improved their output of concepts.

An important fact to be noted is that solutions that came from the use of TRIZ tended to be used transversally, being applied to other axes. For example, idea 22 is based on TRIZ and the details of the solution were also used later in the session to create ideas 42 and 52. Without the use of TRIZ, only 3 solutions would have been created for the axes 2, 4 and 5. But with the addition of TRIZ, 6 solutions were generated in total.

After the session, all these solutions were graded on three criteria: creativity (whether the idea was original), feasibility (if the idea could be designed with the current knowledge at hand) and pertinence (whether the idea responded to the problematic). The grades were attributed by two members of the team based on their perception of the idea. Each idea are graded between 1 (the lowest grade) and 5 (the highest grade). Each idea would be graded between 1 (the lowest grade) and 5 (the highest grade).

For example, ideas based on the first axis of solution revolved around the use of cables to actuate the limbs. As few papers or products explore this kind of solutions, the ideas were considered more creative than ideas based around the second axis which revolves around the use of motors linked to a rigid exoskeleton that is widely represented in both papers and commercial products. But the ideas using motors were considered more feasible as there is a lot of papers explaining their implementation and control in exoskeleton.

Table 2 presents the mean and the standard deviation for ideas based on TRIZ and creativity in order to determinate the influence of TRIZ on the ideas.

\begin{tabular}{|l|c|c|c|c|c|c|}
\hline Criteria & \multicolumn{2}{|c|}{ Creativity } & \multicolumn{2}{c|}{ Feasibility } & \multicolumn{2}{c|}{ Pertinence } \\
\hline Use of TRIZ & No & Yes & No & Yes & No & Yes \\
\hline Mean & 3,80 & 3,20 & 3,00 & 4,11 & 3,40 & 3,78 \\
\hline Standard deviation & 1,64 & 1,09 & 1,87 & 1,76 & 1,34 & 0,67 \\
\hline Min & 1 & 1 & 1 & 1 & 2 & 3 \\
\hline Max & 5 & 5 & 5 & 5 & 5 & 5 \\
\hline
\end{tabular}

Table 2 - Mean and standard deviation of the solutions with Classical creativity and TRIZ creativity 
Ideas based on TRIZ tend to be less creatives but have a pertinence and a feasibility superior to ideas based on creativity. The standard deviation with TRIZ is also always inferior than without TRIZ.

\section{Conclusion}

During our case study, TRIZ was used to enhance the design thinking process by identifying technical difficulties that would need special care. Rather than using the problems solving elements of the methodology, the design process used the problem analysis elements (ideal results, sub and super systems analysis and contradictions generation) to create a pool of knowledge to use during the generation of solutions.

The TRIZ methodology also helped us focus the ideation process. Rather than imagining lots of solutions detached from reality, it helped the team understand the challenges and use the creativity to solve those difficulties. Integrating TRIZ notions in the methodology also helped separating the different levels of the project. Working with the notion of sub systems and their ideality, the participants easily identified the different challenges and used the flexible structure of design thinking to solve separately the problems.

Future work would consist to validate those results with other creativity session. Each idea would be graded as seen in the results part of the paper and compared to our preliminary results presented in this article in order to evaluate the pertinence of TRIZ in our methodology for the healthcare environment.

This methodology aims at perfecting the design process in the healthcare environment but is not limited to it. We believe it can be applied to other activity sectors where the human factor is highly relevant, as within the healthcare sector with the contribution of the doctors and the patients.

\section{Acknowledgments}

This research was carried out within the framework of the RehaByExo project supported by the Carnot Institute ARTS.

\section{References}

1. World Health Organization, Stroke, Cerebrovascular accident. (2019) : https://www.who.int/topics/cerebrovascular_accident/en/

2. Jørgensen HS, N. H.-L. (1995). Outcome and Time Course of Recovery in Stroke, Arch Phys Med Rehabil. 
3. Bourgeais, AL., Guay, V., Laroudie, F., Marsal, C., Thevenin-Lemoine, E. (2009) Informations et programme d'exercices dans les suites d'un AVC. Livret destiné aux patients, aux aidants et aux rééducateurs. ISBN : 978-2-7466-2220-3

4. Dobkin, B. H. (2005, Avril). Rehabilitation after Stroke. The new england journal of medicine, pp. 1677-1684.

5. Ferrucci, L., Bandinelli, S., Guralnik, J. M., Lamponi, M., Bertini, C., Falchini, M., \& Baroni, A. (1993). Recovery of functional status after stroke. A postrehabilitation follow-up study. Stroke, 24(2), 200-205.

6. Haute Autorité de Santé (2012). Accident vasculaire cérébral : méthodes de rééducation de la fonction motrice chez l'adulte.

7. Ali, H. (2014). Bionic exoskeleton: history, development and the future. In IOSR Journal of Mechanical and Civil Engineering (IOSR-JMCE), International Conference on Advances in Engineering \& Technology.

8. Anam, K., \& Al-Jumaily, A. A. (2012). Active exoskeleton control systems: State of the art. Procedia Engineering, 41, 988-994.

9. Burgar, C. G., Lum, P. S., Shor, P. C., \& Van der Loos, H. M. (2000). Development of robots for rehabilitation therapy: The Palo Alto VA/Stanford experience. Journal of rehabilitation research and development, 37(6), 663-674.

10. Rajesh, S. M. (2013). Design of human exo-skeleton suit for rehabilitation of hemiplegic people. Procedia Engineering, 51, 544-553.

11. LEE, K. (s.d.). Innovative Design Thinking Process with TRIZ.

12. Faste, R., Roth, B., \& Wilde, D. (1993). Integrating Creativity into the Mechanical Engineering Curriculum. ASME Resource Guide to Innovation in Engineering Design. American Society of Mechanical Engineers, New York.

13. Doorley, S., Holcomb, S., Klebahn, P., Segovia, K., \& Utley, J. (2018). Design thinking bootleg. Stanford.

14. Dorst, K. (2011). The core of 'design thinking' and its application. Design studies, 32(6), 521-532.

15. Dym, C. L., Agogino, A. M., Eris, O., Frey, D. D., \& Leifer, L. J. (2005). Engineering design thinking, teaching, and learning. Journal of engineering education, 94(1), 103-120.

16. Mann, D. (2001). An introduction to TRIZ: The theory of inventive problem solving. Creativity and Innovation Management, 10(2), 123-125. 